\section{More on citation analysis}

SIR - Further to the letter from Lewison et al. ${ }^{1}$ the recently published Institute for Scientific Information (ISI) list of the most cited papers in the field of soil science $^{2}$ shows how misleading a mere citation count can be.

Out of the nine most cited soils articles, covering the years 1945-89, eight were to methods (804 to 368 citations per paper), mostly improvements on previous techniques, and only one to a lengthy review article of a multidisciplinary nature, which duly reached the list of 'citation classics' in Current Contents. The list does not include a single outstanding paper heralding significant advances in behaviour or process understanding of soil genesis or its more applied aspects.

Nobody would claim that in soil or other experimental sciences the methodology papers represent major scientific breakthroughs. These papers were merely fortunate that their methods had not been further improved and they therefore continue to be quoted. Soil science, like other Earth sciences, is both a basic science and regionally and spatially variable. Although its fundamental tenets and the methodology used are equal everywhere, significant advances in pedology are frequently of only regional importance and so may not be frequently cited.

In other fields, such as palaeontology, where precedence and the first report of an observation are important, the rules of citation also do not favour the most cited paper as representing the highest quality. In such cases, the numbers of citations, no matter how indexed, do not reflect quality or even usage, but are preliminary and incomplete guides to it. I have recently completed a study on paradigm shifts in soil science and doubt that all of the selected outstanding contributions would have made the list of most cited papers or books ${ }^{3}$.

There are many similar examples in other fields. No doubt insight in addition to rigorous number manipulation is after all equally important when evaluating a citation track record.

\section{Dan H. Yaalon}

Institute of Earth Sciences,

Givat Ram Campus,

The Hebrew University,

Jerusalem 91904, Israel

SIR - I agree with Giovanni Motta ${ }^{4}$ that impact factor (IF) and citation index (CI) can be misleading. They often reflect not the quality of a piece of scientific work but the diffusion of the journal in which the work is published. But IF and CI values carry significant weight, and researchers compete fiercely to publish in journals with a high IF.

The dispute about how to judge scien- tific work when appointing academics will continue for years to come. Unfortunately, in Italy, no account is taken of evaluation of academic disposition and scientific work in selecting candidates for Italian universities ${ }^{5}$. Indeed, it has been consistently shown that the most productive and respected candidates were failed in favour of candidates of lesser scientific merit.

Given the present practice, bearing the right surname, or having been a portaborse ('bag-carrier') to powerful professors, is more important than scientific prowess.

I agree that the selection process should not be based on totally mechanistic criteria. On the other hand, the Italian practice of leaving it totally in the hands of the panellists has resulted in the appointment to senior positions of candidates who have published hundreds of papers of dubious scientific value in non-refereed journals. The process of evaluation of a candidate's scientific work should not be regulated by tight laws, but neither should it be totally free. In countries without a damning past record of favouritism and nepotism, such as the United Kingdom, academic appointments are made 'in camera', and are seldom disputed.

As well as dedicating their time to bibliometric studies, researchers should probably investigate the heritability of the title of 'professor' in Italian academic families, which are well known and present in every university, especially in medical faculties. My conclusion, for the time being based on slightly more than anecdotal evidence, is that it must be an autosomal dominant gene or group of genes with an extremely high penetration.

\section{Nicola Maffulli}

Department of Orthopaedics and Traumatology,

Chinese University of Hong Kong,

Prince of Wales Hospital,

Shatin, New Territories, Hong Kong

1. Lewison, G., Anderson, J. \& Jack J. Nature 377, 671 (1995).

2. McDonald, P. (ed.) The Literature of Soil Science (Cornell Univ. Press, 1994)

3. Yaalon, D. H. Paradigms in the History of Soil Science (in the press).

Motta, G. Nature 376, 720 (1995).

5. Gaetani, G. F. \& Ferraris, A. M. Nature 353, 10 (1991).

\section{Spanish practices}

SIR - Further to the letter from Vicente Rodilla (Nature 376, 290; 1995) about hiring practices in Spanish universities, I would like to point out that, paradoxically, there appears to be a negative correlation at present between any objective and reasonable measurement of academic achievement in Spain and the probability of getting a permanent lectureship.

The main reason is that, whenever a vacancy occurs in a university department, there is almost always a local candidate. If an outsider does not have an better academic record than the local candidate, there is little point in him or her applying for the post. Indeed, it is often the case that the local candidate is the only applicant, particularly if it appears that the selection has been decided in advance.

Furthermore, the most influential members of the five-person appointment committee in reaching a decision are the two members representing the university concerned, as they need the support only of one of the three other members for a particular candidate. These two will have little reason to select a candidate not favoured by the university, and will have little incentive to choose a candidate purely on merit, as their own situation is unlikely to be affected by their colleagues' achievements. Nor are any objective evaluations of university departments made public, so that the merits of a particular university cannot be assessed in advance by potential students.

Measures that might increase the teaching and research performance of Spanish universities include a public, external evaluation of the teaching and research activities of each department and the creation of a single applications process for all universities, open to all applicants in fair competition (in practice, there are currently quotas for non-local students). Both proposals would promote competition between universities. In addition, deans should be involved in all appointments, universities should have more salary grades, with internal promotion based on an external assessment of an individual's academic record, and appointment committees should include members from outside the university concerned.

Miguel Perez-Enciso

UdL-IRTA,

25198 Lleida, Spain

\section{Still there}

SIR - The 520 scientists who attended the 22nd International Cosmic Ray Conference in Dublin from 11 to 23 August 1991, which was hosted by the Dublin Institute for Advanced Studies, must have been astonished to read in your recent leading article (Nature 378, 222; 1995) that “... after the Second World War...the Dublin Institute for Advanced Studies was active in a variety of modern fields, cosmic rays for example. But all trace of that endeavour had vanished by the mid-1960s...".

Cosmic ray physics is being actively pursued in the Dublin Institute for Advanced Studies as it has been since the establishment of the section in 1947.

Luke O'C. Drury

School of Cosmic Physics,

Dublin Institute for Advanced Studies,

5 Merrion Square, Dublin 2, Ireland 